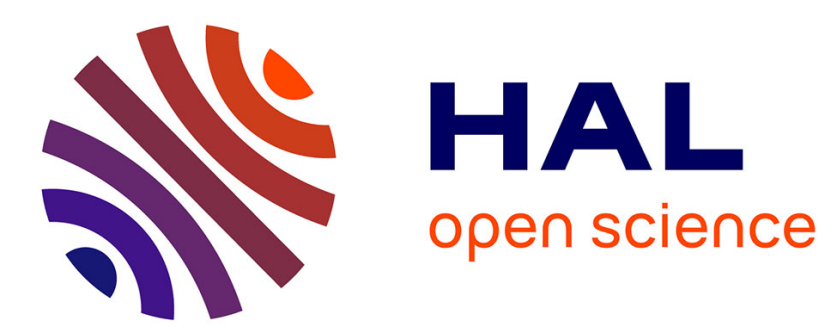

\title{
Determining Crack Aperture Distribution in Rocks Using the 14 C-PMMA Autoradiographic Method: Experiments and Simulations
}

P. Sardini, S. Billon, M. Siitari-kauppi, J. Kuva, L. Fonteneau, L. Caner, Marine Bonnet

\section{To cite this version:}

P. Sardini, S. Billon, M. Siitari-kauppi, J. Kuva, L. Fonteneau, et al.. Determining Crack Aperture Distribution in Rocks Using the 14 C-PMMA Autoradiographic Method: Experiments and Simulations. Journal of Geophysical Research: Solid Earth, 2020, 125 (1), 10.1029/2019JB018241 . hal-03194376

\section{HAL Id: hal-03194376 https://hal.science/hal-03194376}

Submitted on 2 Jan 2022

HAL is a multi-disciplinary open access archive for the deposit and dissemination of scientific research documents, whether they are published or not. The documents may come from teaching and research institutions in France or abroad, or from public or private research centers.
L'archive ouverte pluridisciplinaire HAL, est destinée au dépôt et à la diffusion de documents scientifiques de niveau recherche, publiés ou non, émanant des établissements d'enseignement et de recherche français ou étrangers, des laboratoires publics ou privés. 


\author{
RESEARCH ARTICLE \\ 10.1029/2019JB018241 \\ Key Points: \\ - A new method for determining \\ multiscale crack apertures in rocks \\ is proposed \\ - The method is based on \\ impregnation of connected porosity \\ with a radioactive resin: ${ }^{14} \mathrm{C}$-PMMA \\ (Plexiglas) \\ - Crack apertures are obtained from \\ the analysis of the resulting \\ autoradiography
}

Supporting Information:

- Supporting Information S1

Correspondence to:

M. Bonnet,

marine.bonnet@univ-poitiers.fr

Citation:

Bonnet, M., Sardini, P., Billon, S. Siitari-Kauppi, M., Kuva, J., Fonteneau, L., \& Caner, L. (2020). Determining crack aperture distribution in rocks using the ${ }^{14} \mathrm{C}$-PMMA autoradiographic method: Experiments and simulations. Journal of Geophysical Research: Solid Earth, 125, e2019JB018241. https://doi. org/10.1029/2019JB018241

Received 25 JUN 2019 Accepted 24 DEC 2019 Accepted article online 26 DEC 2019

(C)2019. American Geophysical Union. All Rights Reserved.

\section{Determining Crack Aperture Distribution in Rocks Using the ${ }^{14}$ C-PMMA Autoradiographic Method: Experiments and Simulations}

\author{
M. Bonnet ${ }^{1}$, P. Sardini ${ }^{1}$, S. Billon ${ }^{2}$, M. Siitari-Kauppi ${ }^{3}$, J. Kuva ${ }^{4}$, L. Fonteneau ${ }^{5}$, and L. Caner ${ }^{1}$ \\ ${ }^{1}$ IC2MP HydrASA Laboratory, UMR CNRS 7285, B35, University of Poitiers, TSA 51106, Poitiers, France, ${ }^{2}$ ERM \\ Company, Poitiers, France, ${ }^{3}$ Department of Chemistry, University of Helsinki, Helsinki, Finland, ${ }^{4}$ Geological Survey of \\ Finland, Espoo, Finland, ${ }^{5}$ Corescan Pty Ltd, Western Australia, Australia
}

\begin{abstract}
Because cracks control the global mechanical and transport properties of crystalline rocks, it is of a crucial importance to suitably determine their aperture distribution, which evolves through alteration processes and rock weathering. Due to the high variability of crack networks in rocks, a multiscale approach is needed. The ${ }^{14} \mathrm{C}$-PMMA (polymethylmethacrylate) method was developed to determine crack apertures using a set of artificial crack samples with different controlled apertures and tilt angles and also using Monte Carlo simulations. The experiments and simulations show the same result: the estimation of apparent aperture $w_{A}$ was successful regardless of tilt angle, even if the estimates are less accurate for low tilt angles $\left(<30^{\circ}\right)$. The uncertainties on the estimation of the real crack aperture $w_{R}$ arise from the unknown tilt angle. The ability of the ${ }^{14} \mathrm{C}$-PMMA autoradiography method to estimate crack aperture distributions in rock samples was successfully confirmed on a sample of Grimsel granodiorite.
\end{abstract}

\section{Introduction}

Cracks are ubiquitous structures of rocks, existing in unweathered rock matrices or generated by brittle deformation along faults in a damaged zone (Brace \& Bombolakis, 1963; Cox \& Scholz, 1988a, 1988b; Vermilye \& Scholz, 1995; White \& White, 1983). They strongly control transport properties of rocks by acting as preferential pathways for fluids and solutes (Hakami \& Larsson, 1996; Sausse et al., 2001; Stoll et al., 2018). Such circulation inside intact rock induces changes in rock mineralogy and pore space geometry fostering rock weathering (Kranz, 1983; Sausse et al., 2001; Velde \& Meunier, 2008). Weathering impacts the transport properties and permeability of the rock (Brown, 1989; Brown et al., 1998; Regenauer-Lieb et al., 2013b, 2013a; Tsang \& Witherspoon, 1981, 1983), and the diffusion and transport of solutes into the rock (Bear et al., 1993; Grisak \& Pickens, 1980, 1981; Hellmuth et al., 1991 , 1994), because of the induced dissolution/precipitation reactions (Jamtveit et al., 2009 , 2011; Putnis, 2002, 2009; White et al., 2001). These changes in pore geometry and connectivity during rock alteration are coupled with changes of mechanical properties (Ghaffari et al., 2013; Ghaffari \& Young, 2011; Rock, 2010; Rossi \& Graham, 2010).

A proper determination of crack aperture distribution is of great importance for better understanding the movement of fluids and solutes, as well as the fluid/rock interactions related to mechanical damaging (Mazurier et al., 2016). Classical 2-D (optical microscopy, scanning electron microscopy [SEM]) and 3-D (X-ray computed tomography [XRCT]) methods are not fully adapted to the multiscale nature of crack apertures (Johns et al., 1993; Ketcham \& Carlson, 2001; Mazurier et al., 2016; Sardini et al., 2014). Indeed, cracks often have apertures ranging from micrometer to centimeter scale within the same rock sample. SEM allows one to determine apparent crack apertures higher than $\sim 0.1 \mu \mathrm{m}$, but because of its limited field of view it does not allow the determination of a connected crack network at centimeter sample scale. Computing large mosaics of SEM images is however possible for thin section size samples (up to several square centimeters areas) at high resolution (Buckman et al., 2017), but it is time consuming compared to the ${ }^{14} \mathrm{C}$-labeled polymethylmethacrylate $\left({ }^{14} \mathrm{C}\right.$-PMMA) method. XRCT has some of the same limitations as SEM; voxel size can be quite low $(0.1 \mu \mathrm{m})$, but total volume size is limited to about 2,000 times the voxel size.

To overcome these limitations, an approach using the ${ }^{14}$ C-PMMA method (Hellmuth et al., 1993 , 1994; Hellmuth \& Siitari-Kauppi, 1990; Sammaljärvi, 2017; Sardini et al., 2006 , 2015; Siitari-Kauppi, 2002) is proposed. The ${ }^{14} \mathrm{C}$-PMMA method consists of impregnating a sample with liquid ${ }^{14} \mathrm{C}$-labelled methylmethacrylate $\left({ }^{14} \mathrm{C}-\mathrm{MMA}\right)$ monomer, polymerizing the monomer in the pore space, and autoradiography of the 
impregnated sample after sawing and polishing, which gives a connected porosity map of the studied rock section (Kelokaski et al., 2006; Leskinen et al., 2007; Oila et al., 2005; Voutilainen et al., 2012). The advantage of this method is its spatial resolution which is $20 \mu \mathrm{m}$ with ${ }^{14} \mathrm{C}$. However, it is important to keep in mind that if the crack network is very dense, it will be very difficult to discern between the cracks. Thus, the lowest distance between two parallel cracks that can be analyzed is equal to the resolution of the method, here $20 \mu \mathrm{m}$.

Previous work from Sardini et al. (2014) and Kuva et al. (2015) provided the basis for quantifying crack apertures using the ${ }^{14} \mathrm{C}$-PMMA method. Sardini et al. (2014) conducted preliminary simulations using a simplified Monte Carlo approach to calculate crack apertures from autoradiographic signals. This approach was used to determine the influence of pixel size and crack aperture on the resulting autoradiographic activity profiles but remains qualitative. Then Kuva et al. (2015) used artificial crack samples with known crack apertures (from $<1$ to $270 \mu \mathrm{m}$ ) impregnated with ${ }^{14} \mathrm{C}$-labeled PMMA radioactive resin to determine the test and refine the results of the simulations. However, both papers were limited to cracks tilted perpendicularly to the autoradiographic plane. More recently, Mazurier et al. (2016) used the ${ }^{14}$ C-PMMA method for estimating crack apertures of granodiorite from Bishop Creek, using a simplified approach. They also compared their results with results obtained through XRCT. One of their conclusions was the need to better calibrate the quantification of real crack apertures through the use of ${ }^{14} \mathrm{C}$-PMMA autoradiographic method.

To this end, we propose here an advanced calibration of the ${ }^{14} \mathrm{C}$-PMMA autoradiographic method for quantifying real crack apertures by taking into account the variability of tilt angle encountered in natural rock samples. The first goal of this paper is to propose a more robust quantitative simulation method of activity profiles from ${ }^{14} \mathrm{C}$-PMMA autoradiographs. The Geant4 toolkit was chosen for 3-D simulation of the energy deposited in the autoradiographic film. A wide range of crack apertures (from 0.1 to $1,000 \mu \mathrm{m}$ ) and tilt angles (from $10^{\circ}$ to $90^{\circ}$ ) were simulated to evaluate the combined effects of aperture and tilt angle on the energy profile created by $\beta^{-}$emissions of ${ }^{14} \mathrm{C}$-PMMA on the film. The second goal of this paper was to experimentally study the influence of tilt angles on this quantification following the work of Kuva et al. (2015).

These effects were analyzed by (1) the full width at half maximum ( $F W H M$ ) and (2) the maximal normalized energy $\left(E / E_{0}\right)_{\max }$ or activity $\left(A / A_{0}\right)_{\max }$ on simulated or experimental profiles. The simulated profiles were compared to those derived from the experiments.

Finally, this method was applied on a granodiorite rock sample from Grimsel test site.

\section{Materials and Methods}

The figures, tables, and texts referred to with the letter "S" in front of their number are presented in the supporting information.

Cracks with apertures below $50 \mu \mathrm{m}$ are referred to as microcracks, and cracks with apertures equal to or above $50 \mu \mathrm{m}$ are referred to as macrocracks. This empirical distinction was made because of their specific autoradiographic profiles. Macrocracks provide thick profiles with a variable FWHM and high normalized energy $\left(E / E_{0}\right)$ or activity $\left(A / A_{0}\right)$. Conversely, microcracks provide thinner profiles with little variation in $F W H M$ and variable normalized energy $\left(E / E_{0}\right)$ or activity $\left(A / A_{0}\right)$. Macrocracks and microcracks are thus separated from each other by a threshold of the normalized activity energy $\left(E / E_{0}\right)$ or $\left(A / A_{0}\right)$ where a change in the $F W H M$ of their autoradiographic profile is observed or is no longer observed.

\subsection{Simulations}

\subsubsection{Simulation of ${ }^{14} \mathrm{C}-\mathrm{PMMA}$ Filled Artificial Cracks With Geant4}

Geant4 (GEometry ANd Tracking 4) is a toolkit developed by CERN (European Organization for Nuclear Research) in 1998 (Agostinelli et al., 2003) for the simulation of transport of particles through matter in 3D, using Monte Carlo methods. The version used for this study was Geant4.10.02.p02.

It was used for the simulation of the transport of $\beta^{-}$particles emerging from the ${ }^{14} \mathrm{C}$-labelled PMMA resin filling a crack to the autoradiographic film, through PMMA or glass, representing the experimental glass plate system described below (section 2.2).

The 3-D geometry of the autoradiographic system defined for the simulations (Figure 1) is described in detail in the supporting information (Text S1). An important constant parameter to consider for this geometry is the maximal range of $\beta^{-}$particles in PMMA (rangemax, $R_{m}$ ) which controls the volume of the simulated 


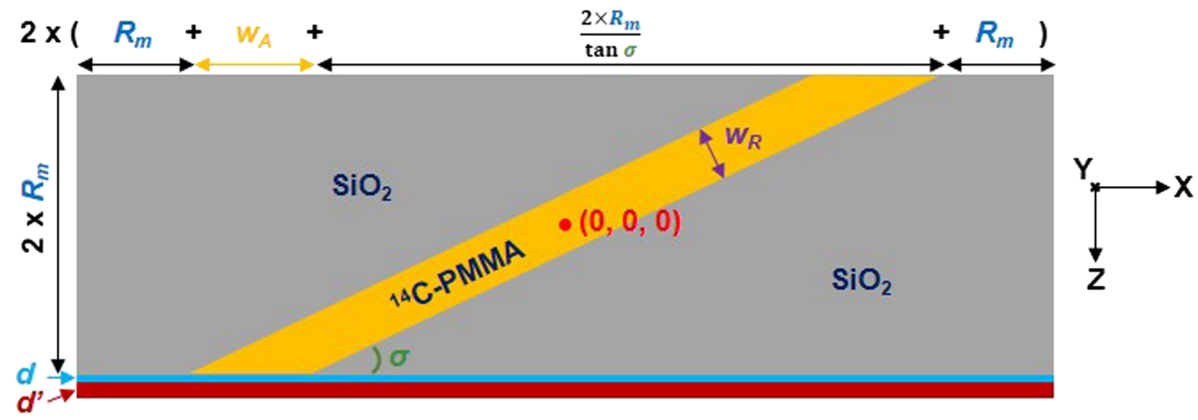

Figure 1. Schematic of a crack between two glass plates and topped with an autoradiographic film for the simulations. The glass plates are in gray, the PMMA-filled crack in yellow, and the emulsion and the plastic parts of the autoradiographic film in cyan and red, respectively. $\left(w_{R}=\right.$ real crack aperture $(\mu \mathrm{m}) ; w_{A}=$ apparent crack aperture $(\mu \mathrm{m}) ; \sigma=$ tilt angle (degree); $R m=\operatorname{rangemax}(\mu \mathrm{m}) ; d=$ emulsion thickness $(\mu \mathrm{m}) ; d^{\prime}=$ plastic thickness $\left.(\mu \mathrm{m})\right)$ The detailed description of this system is presented in the supporting information (Text S1).

sample. The maximum propagation distance $\left(R_{m}\right)$ was previously determined by an independent housemade Geant4 program. This program simulates the propagation of ${ }^{14} \mathrm{C} \beta^{-}$particles from a source point into a large medium made of pure PMMA. The simulations gave a rangemax $\left(R_{m}\right)$ of $278 \mu \mathrm{m}$ for ${ }^{14} \mathrm{C} \beta^{-}$ particles in pure PMMA.

For each simulation, the energy profile created by $\beta^{-}$particles on the film emulsion around the crack is obtained. A wide range of real crack apertures (from 0.1 to $1,000 \mu \mathrm{m}$ ) and tilt angles (from $10^{\circ}$ to $90^{\circ}$ ) were simulated. The resolution $b$ of the profiles was set to $2 \mu \mathrm{m}$.

To obtain smooth profiles and sufficient statistics, $N_{T}=10^{7}$ particles were used to calculate all the simulated profiles. For macrocracks, the profiles obtained with $10^{7}$ particles were not completely smooth. However, the observed fluctuations were not problematic for the data processing presented below.

\subsubsection{Data Processing of the Geant4 Profiles Using C++ Language With the IDE Code::Blocks}

Profiles extracted from Geant4 simulations were processed using C++ language with the IDE Code::Blocks (http://www.codeblocks.org/). Prior to the analyses, the energy profiles $E(x)$ were normalized to their expected asymptotic values $\left(E_{0}\right)$ obtained for a large sample made of pure PMMA. For instance, for cracks with tilt angle $\sigma=90^{\circ}$ and $w_{R}>2 \times R_{m}, E(x) / E_{0}$ should reach 1 at the central axis of the crack. The calculations of $E_{0}$ are shown in more detail in the supporting information (Text S2). It was checked that the maximum of the normalized profiles $E(x) / E_{0}$ converged to 1 for thick cracks.

Profiles were analyzed for determining their maximum $\left(E / E_{0}\right)_{\max }$, which was used to calculate (1) the $F W H M$ (Figure S1) and (2) the mean value of $E(x) / E_{0}$ on windows centered on $\left(E / E_{0}\right)_{\max }$. The window size corresponds to the pixel size in the film. It ranged from 10 to $100 \mu \mathrm{m}$, as presented in Figure S1. Moreover, an asymmetry coefficient $g_{1}$ of profiles was calculated using the Fisher coefficient (Dagnelie, 1992) (calculations detailed in Text S2).

\subsection{Experiments}

\subsection{1. ${ }^{14} \mathrm{C}$-PMMA Impregnation}

The ${ }^{14} \mathrm{C}$-PMMA method is based on the impregnation of ${ }^{14} \mathrm{C}$-MMA liquid monomer into the connected pore network of a rock. The MMA molecule has physicochemical properties similar to those of water, making it a molecule that is able to mimic its behavior, that is, its infiltration, in tiny pores of rocks (Oila et al., 2005; Sardini et al., 2006; Siitari-Kauppi, 2002).

The monomer resin is labeled with radioactive ${ }^{14} \mathrm{C}$ to make it a tracer that allows, with the use of autoradiography, the mapping of connected porosity of rocks. ${ }^{14} \mathrm{C}$ is a radioactive isotope which emits $\beta^{-}$particles with a maximum energy of $156 \mathrm{keV}$ and a half-life of 5,720 years, which permits autoradiography experiments without any time constraints.

MMA was used to impregnate a series of artificial cracks with a known aperture. These cracks were created between two glass plates, using Mylar or Al-foils as spacers. Varying spacer thicknesses were used to create 
Table 1

Values of Desired $w_{D}$, Real $w_{R}$, and Apparent $w_{A}$ (Measured by SEM) Apertures of Perpendicular and Tilted Artificial Cracks and Their Associated Activity

\begin{tabular}{|c|c|c|c|c|c|c|c|c|c|c|c|c|c|c|c|c|c|}
\hline \multirow[b]{2}{*}{ Desired aperture $w_{D}(\mu \mathrm{m})$} & \multicolumn{7}{|c|}{ Macrocracks } & \multicolumn{10}{|c|}{ Microcracks } \\
\hline & 270 & & 180 & & 90 & 50 & & 30 & & 15 & & 6 & & 0.8 & & 0 & \\
\hline Tilt angle $\sigma$ (degrees) & 90 & 10 & 90 & 20 & 90 & 90 & 40 & 90 & 70 & 90 & 60 & 90 & 50 & 90 & 40 & 90 & 45 \\
\hline SEM aperture $(\mu \mathrm{m})$ & $w_{R}$ & $w_{A}$ & $w_{R}$ & $w_{A}$ & $w_{R}$ & $w_{R}$ & $w_{A}$ & $w_{R}$ & $w_{A}$ & $w_{R}$ & $w_{A}$ & $w_{R}$ & $w_{A}$ & $w_{R}$ & $w_{A}$ & $w_{R}$ & $w_{A}$ \\
\hline & 258 & 2160 & 189 & 660 & 96 & 56 & 143 & 31 & 33 & 12.4 & 18 & 10.4 & 11 & 9.7 & 23 & 4.4 & 6.4 \\
\hline$A_{0}(\mu \mathrm{Ci} / \mathrm{ml})$ & 12.5 & & 12.5 & & 12.5 & 12.5 & & 4.3 & & 4.3 & & 4.3 & & 4.3 & & 4.3 & \\
\hline
\end{tabular}

the apertures (Kuva et al., 2015) (Table 1). The glass plates with artificial cracks were cut with different tilt angles $\sigma$ (ranging from $10^{\circ}$ to $90^{\circ}$ ) to the crack surface. The cut surfaces were carefully polished in order to optimize the contact between the sample and the autoradiographic film. The samples were cut to fit the dimensions ( $x, y$ directions) of the autoradiographic film (i.e., $17.5 \mathrm{~cm} \times 20.5 \mathrm{~cm}$ for a Kodak BioMax $\mathrm{MR}^{\circledR}$ ) and with a thickness ( $z$ direction) being at least that of the maximal range of the particles emitted (i.e., $278 \mu \mathrm{m}$, the maximal range of $\beta^{-}$of ${ }^{14} \mathrm{C}$ in PMMA).

Desired apertures $w_{D}$ ranged from 0 to $270 \mu \mathrm{m}$ (Table 1). The real apertures $w_{R}$ of the artificial cracks were measured using SEM. $w_{R}$ was found to differ significantly from $w_{D}$, especially for small cracks. For instance, the sample without any Mylar or Al foil between the glass plates $\left(w_{D}=0 \mu \mathrm{m}\right)$ had a $w_{R}=4.4 \mu \mathrm{m}$. The apparent apertures $w_{A}\left(w_{A}=w_{R} / \sin (\sigma)\right)$ were also measured using SEM (Table 1). Initially artificial samples with a null aperture and a $0.8 \mu \mathrm{m}$ aperture $\left(w_{D}\right)$ (for this sample $w_{R}=9.7 \mu \mathrm{m}$ ) were planned. But it was observed that it is not an easy task to obtain the desired aperture when dealing with Mylar or Al-foils as spacers.

\subsubsection{Autoradiography and Digital Image Processing}

The polished impregnated rock surfaces were exposed on Kodak BioMax $\mathrm{MR}^{\circledR}$ autoradiographic films for 8 hr with a ${ }^{14} \mathrm{C}$ calibration series of 10 activities ranging between 0.125 and $9 \mu \mathrm{Ci} / \mathrm{ml}$. The $\beta^{-}$particles emitted by ${ }^{14} \mathrm{C}$ react with the silver bromide (AgBr) grains in the film emulsion, causing darkening of the film proportional to the present activity. The exposure time was considered carefully as a too long exposure time causes film saturation, which happens easily for macrocracks. On the other hand, a too short exposure time is not able to reveal microcracks (Siitari-Kauppi, 2002). In this study, an exposure time of $8 \mathrm{hr}$ was suitable for studying both macrocracks and microcracks at the same time.

The autoradiographs were scanned with a tabletop scanner (Microtek's ArtixScan F1 ${ }^{\circledast}$ ) at different pixel sizes $(84.7,63.5,42.3,31.75$, and $21.17 \mu \mathrm{m})$. A wide range of resolutions was chosen to study its effect on the crack aperture determination. As detailed in Siitari-Kauppi (2002), for each pixel of the film, its gray level was converted to optical density using the calibration series, and then into activity using the Keller and Waser (1982) approach. The reader is invited to consult Siitari-Kauppi (2002) for a detailed description of the procedure.

Finally, the activity of each pixel was normalized by the activity of the pure resin $A_{0}$ (Table 1). For each crack, several profiles of normalized activity $\left(A / A_{0}\right)$ were obtained using Image ${ }^{\circledR}$ software. Each of these profiles were determined perpendicularly to crack axis and then averaged in one profile by realigning the maxima of those profiles. This procedure was applied to each artificial crack profile.

\section{Results}

The simulation results are first presented, followed by the experimental results, and then a comparison between them. Only the effect of the tilt angle is investigated here; more detailed results on only perpendicular cracks (simulation: Figures S2 and S3 and Table S1; and experimental: Figures S4 and S5 and Table S3) are presented in the supporting information. This choice was made because similar results on perpendicular cracks have already been described in previous works (Kuva et al., 2015; Sardini et al., 2014), and they have been successfully reproduced in this study.

For each section (simulation and experimental), results on estimating macrocrack apertures are first presented, followed by those on microcrack apertures. It is important to well understand that the method used for their estimation has to be adapted to each case: (1) on the one hand for the macrocracks and (2) on the other hand for the microcracks. In the first case (1), the FWHM of the energy or activity profile of a macrocrack is used to estimate its aperture, knowing FWHM increases with the increase of the macrocrack 

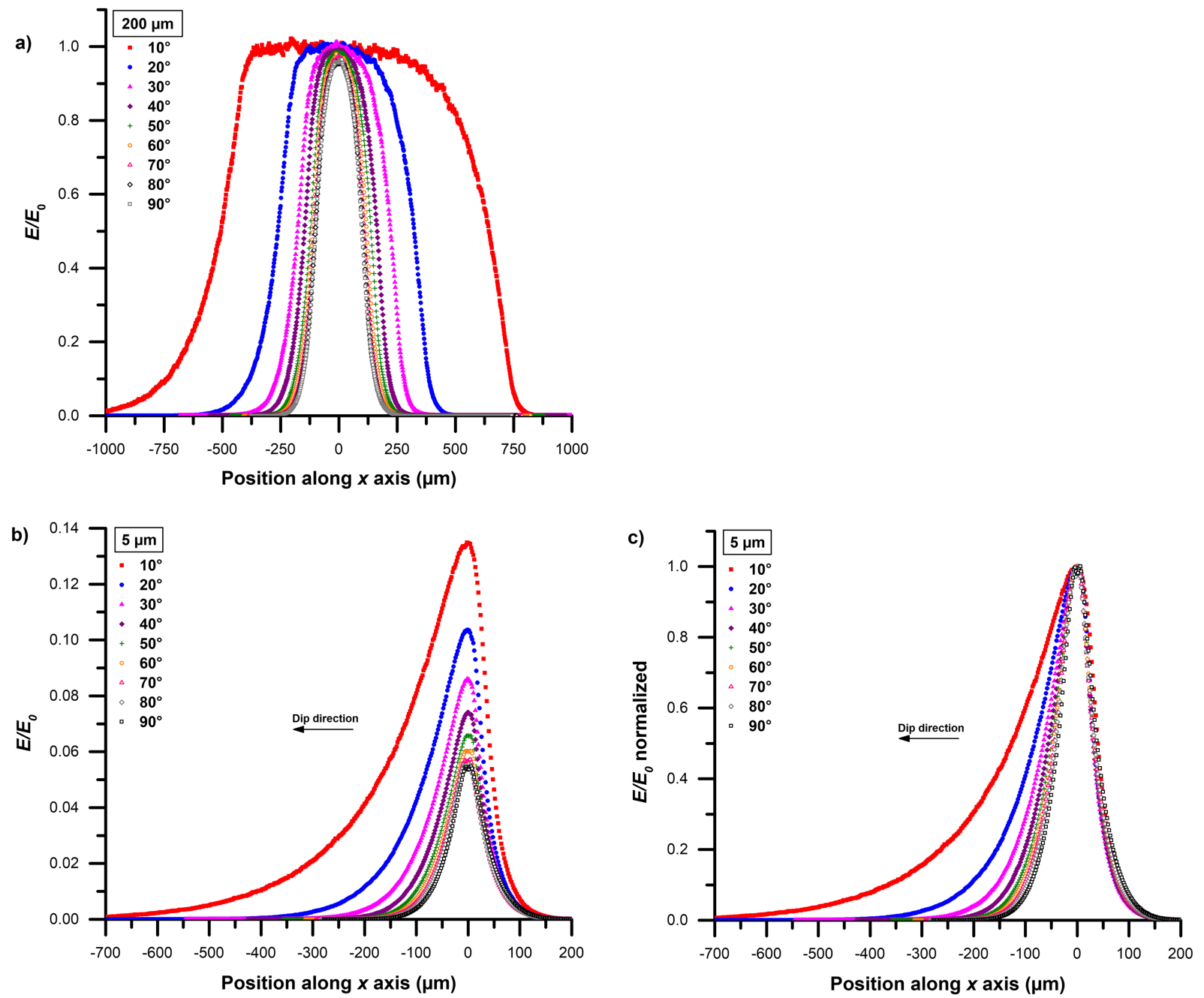

Figure 2. Energy profiles of a $200 \mu \mathrm{m}$ macrocrack (a) and of a $5 \mu \mathrm{m}$ microcrack (b) for $\sigma$ ranging from $10^{\circ}$ to $90^{\circ}\left(N_{T}=10^{7} ; b=2 \mu \mathrm{m}\right)$. (c) Microcrack profiles normalized to the maximum value. Normalizing the macrocrack profiles was not necessary, as their maximum energy value was already equal to 1 .

aperture. In the second case (2), the maximal value $\left(E / E_{0}\right)_{\max }$ or $\left(A / A_{0}\right)_{\max }$ of the normalized energy or activity profile of a microcrack is used to estimate their aperture, knowing this maximal value increases with the increase of the microcrack aperture value while its FWHM is always the same.

In this section, $w_{R}$ refers to the real crack aperture determined by SEM, and the parameters used to estimate $w_{R}$ are identified with the subscript ${ }_{R}$ (e.g., $F W H M_{R}$ ). Similarly, $w_{A}$ refers to the apparent crack aperture determined by SEM, and the parameters used to estimate the apparent crack aperture are identified with the subscript ${ }_{A}$ (e.g., $F W H M_{A}$ ).

\subsection{Simulation Results: Estimating the Crack Apertures}

Energy profiles for a macrocrack $\left(w_{R}=200 \mu \mathrm{m}\right)$ and a microcrack $\left(w_{R}=5 \mu \mathrm{m}\right)$, using tilt angles ranging from $10^{\circ}$ to $90^{\circ}$, are shown in Figure 2 . The microcrack profiles were normalized to $\left(E / E_{0}\right)_{\max }$ to visualize the possible changes in profile shape. Normalizing the macrocrack profiles was not necessary, as $\left(E / E_{0}\right)_{\max }$ was equal to 1 for all angles.

\subsubsection{Macrocrack}

Macrocrack aperture estimations are presented first. It can be clearly seen that when the tilt angle decreases (from $90^{\circ}$ to $10^{\circ}$ ), the $F W H M_{A}$ of the macrocrack and microcrack profiles increases (Figures 2a-2c). This increase is really significant for low tilt angles (Figure 3a). The apparent $F W H M_{A}$ values are quite constant 

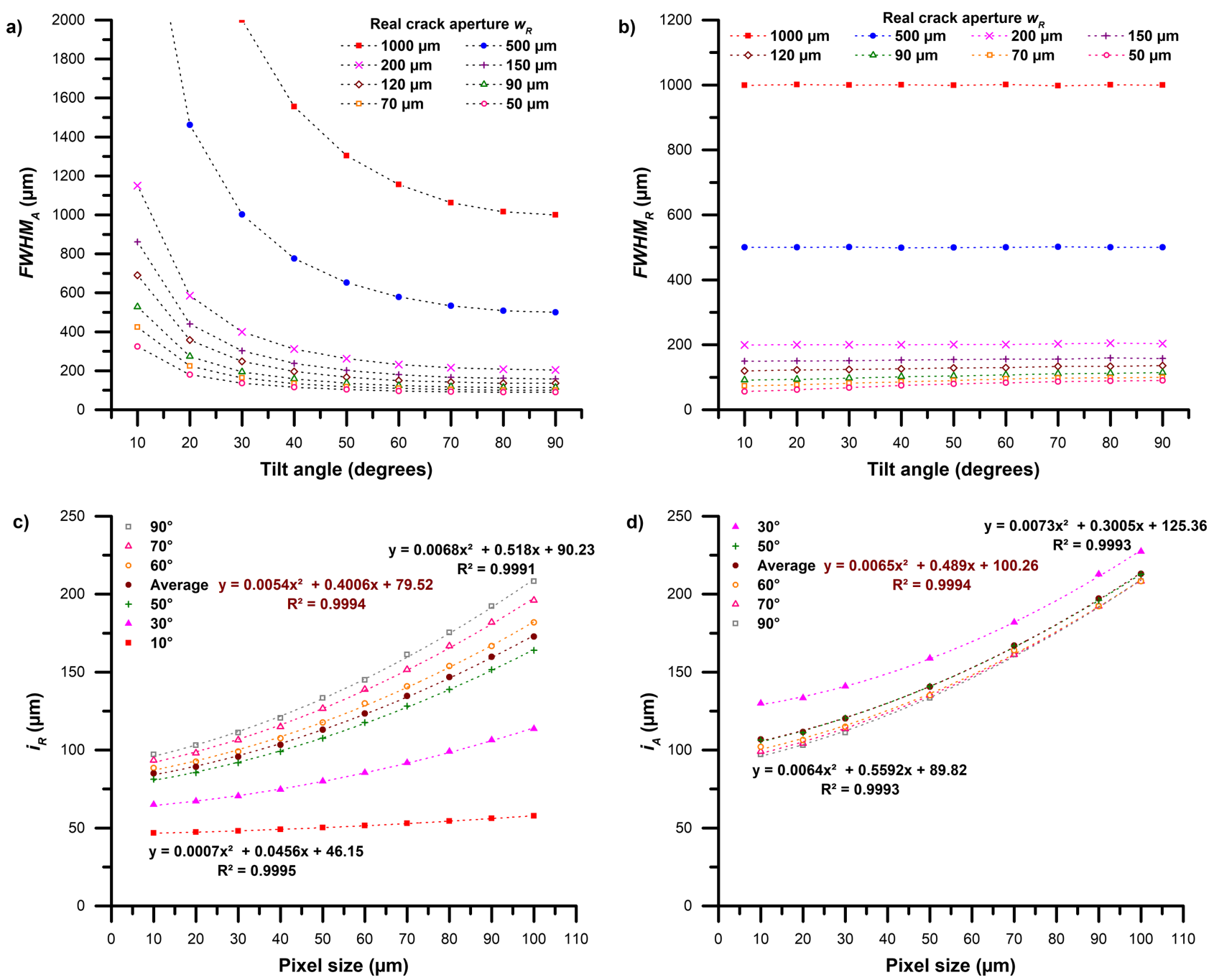

Figure 3. Apparent $F W H M_{A}$ (a) and real $F W H M_{R}$ (b) of macrocrack energy profiles as a function of tilt angle $\left(N_{T}=10^{7} ; b=2 \mu \mathrm{m}\right)$. Real $i_{R}$ (c) and apparent $i_{A}(\mathrm{~d})$ plotted as a function of pixel size, for different tilt angles. The dotted lines represent a polynomial fit of the data, and their equations are shown $\left(N_{T}=10^{7}\right)$.

for $\sigma>50^{\circ}$. For instance, for $w_{R}=200 \mu \mathrm{m}$, the $F W H M_{A}$ is equal to 204, 216, 262, and $400 \mu \mathrm{m}$ for tilt angles of $90^{\circ}, 70^{\circ}, 50^{\circ}$, and $30^{\circ}$, respectively (Table S2). The measured width $\left(F W H M_{A}\right)$ was corrected to account for the tilt angle using

$$
F W H M_{R}=F W H M_{A} \times \sin (\sigma) .
$$

It is then demonstrated that the $F W H M_{R}$ values obtained from calculated profiles arise from apparent apertures of the macrocracks (Figure 3b). In other words, the $F W H M_{A}$ measured from the energy profiles represents the apparent aperture of the macrocracks.

\subsubsection{Microcrack}

The effect of tilt angle on simulated energy profiles is shown in Figures $2 b$ and $2 c$. For a given aperture, it is observed that the maximum normalized energy value $\left(E / E_{0}\right)_{\max }$ increases with the decrease of the tilt angle (Figure 2b). For example, using a pixel size of $20 \mu \mathrm{m}$ and $w_{R}=5 \mu \mathrm{m},\left(E / E_{0}\right)_{\max }$ is equal to $0.05,0.05,0.06$, and 0.08 for tilt angles of $90^{\circ}, 70^{\circ}, 50^{\circ}$, and $30^{\circ}$, respectively (Table S2). It is seen that $\left(E / E_{0}\right)_{\max }$ remains stable for $\sigma>50^{\circ}$, as previously for macrocracks.

The estimation of real microcrack aperture is possible using the measurement of $\left(E / E_{0}\right)_{\max }$, using the simple relationship 
Table 2

Values of the Maximum Normalized Energy $\left(E / E_{0}\right)_{\max }$ of Simulated Microcrack Profiles for a Pixel Size of $20 \mu m$, for Different Tilt Angles

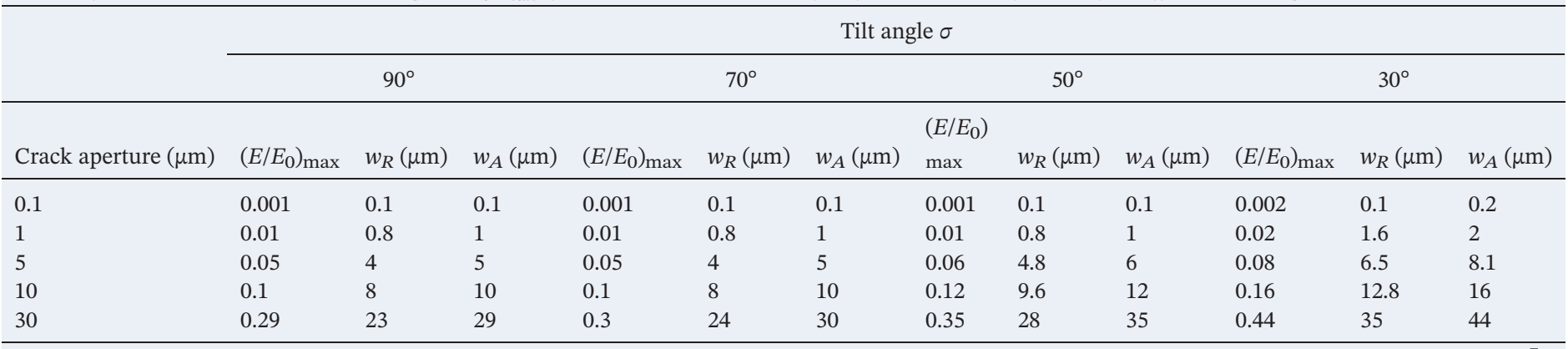

Note. The real crack aperture $w_{R}(\mu \mathrm{m})$ and the apparent crack aperture $w_{A}(\mu \mathrm{m})$ are also indicated (using $i_{R}=80 \mu \mathrm{m}$ and $i_{A}=100 \mu \mathrm{m}$, respectively) $\left(N_{T}=10^{7}\right)$.

$$
w_{R}=i_{R} \times\left(E / E_{0}\right)_{\max },
$$

where $i_{R}(\mu \mathrm{m})$ is obtained by a linear fit. $i_{R}$ is a function of pixel size and was calculated for different tilt angles (Figure $3 \mathrm{c}$ ). $i_{R}$ increases with pixel size, regardless of $\sigma$. As expected, $\left(E / E_{0}\right)_{\max }$ is minimal and $i_{R}$ is maximal when $\sigma=90^{\circ}$. Each data series was approximated by a polynomial fit of the second order (Figure 3c). Whatever the tilt angle, $i_{R}$ stabilizes for pixel sizes lower than about $30 \mu \mathrm{m}$ (Figure 3c). This trend is clearly observed for low tilt angles: For a tilt angle of $10^{\circ} i_{R}$ is nearly constant, regardless of the pixel size. This is explained by the shape of the profile at $10^{\circ}$ which is wider (more extended) than at higher tilt angles; thus, $\left(E / E_{0}\right)_{\max }$ remains relatively high and similar using different window sizes (Figures $2 \mathrm{~b}$ and $2 \mathrm{c}$ ). Therefore, in order to estimate real microcrack apertures directly from $\left(E / E_{0}\right)_{\max }$ at low pixel sizes, an average of $i_{R}=80 \mu \mathrm{m}$ can be used as a first approximation. However, this method remains quite uncertain and dependent on tilt angle. For instance, considering $w_{R}=1 \mu \mathrm{m}$ and a pixel size of $20 \mu \mathrm{m}$, the estimated real aperture $w_{R}$ (equation (2)) ranges from 0.8 to $1.6 \mu \mathrm{m}$ for $\sigma$ ranging from $90^{\circ}$ to $30^{\circ}$ (Table 2).

Moreover, it is stated here that $i_{R}$ obtained from calculated profiles arises from apparent apertures. Then, calculated $i_{A}$ values were also corrected to take into account the tilt angle using

$$
i_{R}=i_{A} \times \sin (\sigma)
$$

where $i_{A}$ and $i_{R}$ are the calculated (apparent) and corrected (real) $i$ values, respectively (Figure 3d). The variation of $i_{A}$ is less dependent on the tilt angle, varying from about 90 to $125 \mu \mathrm{m}$ (for $\sigma=90^{\circ}$ and $30^{\circ}$, respectively, and for pixel sizes $<30 \mu \mathrm{m}$ ) (Figure 3d). An average $i_{A}=100 \mu \mathrm{m}$ can be used with a relatively good accuracy to estimate $w_{A}=i_{A} \times\left(E / E_{0}\right)_{\max }$ (equation (4)), regardless of $\sigma$.

For example, for $w_{R}=1 \mu \mathrm{m}$ and a pixel size of $20 \mu \mathrm{m}$, the estimated apparent aperture $w_{A}$ ranges from 1 to 2 $\mu \mathrm{m}$ for $\sigma$ ranging from $90^{\circ}$ to $30^{\circ}$. This can be considered to be a decent estimation of apparent crack aperture (Table 2).

Furthermore, the tilt angle affects the shape of the crack profiles by forming an asymmetry which is more pronounced when the tilt angle is small. The asymmetry coefficients $g_{1}$ were calculated and are shown in Figure 4. All the values of $g_{1}$ are negative, indicating a spread to the left of the distribution profiles (the distribution is shifted to the right of the median) (Figures $2 b$ and $2 c$ ), except for the highest apertures which have $g_{1}$ values of about 0 , indicating a symmetric distribution profile independent of the tilt angle. Obviously, for a tilt angle of $90^{\circ}$, all the crack profiles are symmetric. The microcracks are affected the most by the asymmetry and have a similar $g_{1}$ coefficient for all tilt angles, while for the macrocracks the higher the aperture, the less it is affected by the tilt angle. A separation between the macrocracks and the microcracks is visible below a tilt angle of $50^{\circ}$, which corresponds to the tilt angle where the $F W H M$ values and the maximum energy values are not stable anymore. So, the value of $g_{1}$ for a tilt angle of $50^{\circ}$ (about -0.3 ) can be used as a tilt detection limit for the microcrack aperture estimation. For microcracks, if $g_{1}$ is lower than -0.3 , then the maximum value of the profile is affected by the tilt angle and so uncertainty on the estimation of the microcrack apertures can occur. 


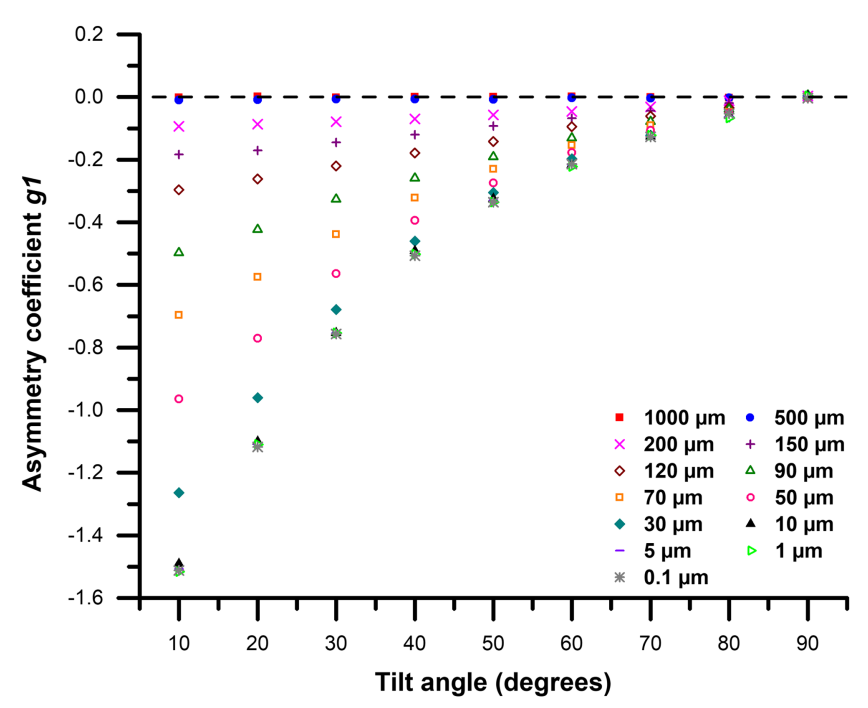

Figure 4. Asymmetry coefficient from the simulated energy profiles plotted as a function of tilt angle $\left(N_{T}=10^{7} ; b=2 \mu \mathrm{m}\right)$. The dotted line represents the limit between a symmetric distribution profile (coefficient value along the line itself), an asymmetric distribution profile spreading to the right (coefficient value above the limit line; the distribution is shifted to the left of the median), and spreading to the left (coefficient value below the limit line; the distribution is shifted to the right of the median).

\subsection{Experimental Results: Estimating the Crack Apertures 3.2.1. Macrocracks}

The maximum value of macrocrack activity profiles $\left(A / A_{0}\right)_{\max }$ is always very close to 1 for any tilt angle (in Figure 5a, the presented profiles are normalized to their maximum value). For instance, for $w_{R}=189 \mu \mathrm{m}$ and $\sigma=20^{\circ}\left(A / A_{0}\right)_{\max }=1$, and for $w_{R}=31 \mu \mathrm{m}$ and $\sigma=70^{\circ}\left(A / A_{0}\right)_{\max }$ $=0.8$. Experimentally, it was not possible to continuously modify $\sigma$ for a given aperture, but the change in profile width, in comparison with the corresponding perpendicular profiles, could be evaluated (Figure S4). The maximum activity value increases with the decrease of $\sigma$, regardless of the real crack aperture (Table S4). For example, for a macrocrack with $w_{R}=189 \mu \mathrm{m}$, the maximum activity value $\left(A / A_{0}\right)_{\max }$ is 0.7 for a perpendicular crack, whereas $\left(A / A_{0}\right)_{\max }$ is 1 for a tilt angle of $20^{\circ}$ (pixel size $=21.17$ $\mu \mathrm{m})$ (Table S4). The progressive increase of $\left(A / A_{0}\right)_{\max }$ with the tilt angle decrease is expected, as when the crack is tilted, the crack volume near the surface is larger and therefore more ${ }^{14} \mathrm{C} \beta^{-}$particles reach the autoradiography surface and increase the peak activity. This feature was also verified through modeling (section 3.1).

The $F W H M_{A}$ values are presented in Figures 6a and 6b. The tilt angle $\sigma$ controls the width of the activity profiles. The $F W H M_{A}$ values agree with the $w_{A}$ measured by SEM and also with $w_{R} / \sin (\sigma)$. This demonstrates the accuracy of the use of the $F W H M_{A}$ to determine $w_{A}$. However, when the cracks have an aperture close to the macro/microcrack limit $(50 \mu \mathrm{m})$, the change in $F W H M_{A}$ is lower. It is clearly demonstrated in Table S4, where the $F W H M_{A}$ of the $31 \mu \mathrm{m}$ aperture profile increases only slightly with the tilt angle, while the $F W H M_{A}$ of the $189 \mu \mathrm{m}$ aperture profile is approximately multiplied by 4 .

\subsubsection{Microcracks}

No effect concerning the experimental shape of microcrack activity profiles related to $\sigma$ was observed (Figure $5 \mathrm{c})$. The $\left(A / A_{0}\right)_{\max }$ of microcrack profiles were plotted as a function of $w_{A}$ for different pixel sizes (Figures $6 \mathrm{c}$ and $6 \mathrm{~d})$. The continuous variation of $\left(A / A_{0}\right)_{\max }$ with the pixel size of the microcracks could not be performed because it was not possible to make different tilt angles on the same artificial crack sample. Furthermore, the $31 \mu \mathrm{m}$ aperture profile is not included here as its maximum activity value could not be reliably measured. The same trend that was observed for the perpendicular microcracks was observed: $\left(A / A_{0}\right)$ max increases linearly with increasing $w_{A}$, and the highest resolution gives the highest maximum activity values. Nevertheless, these values are very close regardless of the resolution used, giving roughly the same value for $i$. The apparent $i_{A}$ values can still be approximated with a second-order polynomial, providing an $i_{A} \sim 70 \mu \mathrm{m}$. The $i_{A}$ values used for this approximation consider different tilt angles and not just one, as specified above. Therefore, only one value of $i_{A}$ is obtained per pixel size, regardless of tilt angle. This $i_{A}$ value is slightly higher than what was obtained for perpendicular microcracks $(55 \mu \mathrm{m})$.

Using an average of the $i$ values for perpendicular and tilted microcracks could be a good compromise for taking into account the wide range of $\sigma$ existing in natural samples.

\subsection{Comparison of Experimental (Activity Profiles) and Simulation (Energy Profiles) Results}

Figure S6 shows a comparison between an experimental activity profile $\left(w_{R}=10.4 \mu \mathrm{m}\right)$ and a simulated energy profile $\left(w_{R}=11 \mu \mathrm{m}\right)$, for $\sigma=90^{\circ}$. Both profiles have a similar maximum activity value $\left(\left(A / A_{0}\right)_{\max }\right.$ $=0.10$ and $\left(E / E_{0}\right)_{\max }=0.9$; Figure S6a) and a similar shape: the $F W H M_{R}$ value is 66 and $64 \mu \mathrm{m}$ for the activity and the energy profiles, respectively (Figure S6b). The profiles agree with each other. Thus, the comparison between experimental and simulation results is accurate.

The FWHM values of experimental and simulated profiles of cracks are compared in Figure 7. It can be seen that the results obtained with the two methods are consistent for both crack types (Figure 7a). For instance, for $\sigma=90^{\circ}$, the $F W H M_{R}$ of a macrocrack $\left(w_{R}=258 \mu \mathrm{m}\right)$ is equal to 235 and $258 \mu \mathrm{m}$ using the experimental and simulated profiles, respectively. Conversely, the $F W H M_{R}$ of the microcrack profiles is constant $(75 \mu \mathrm{m})$, 

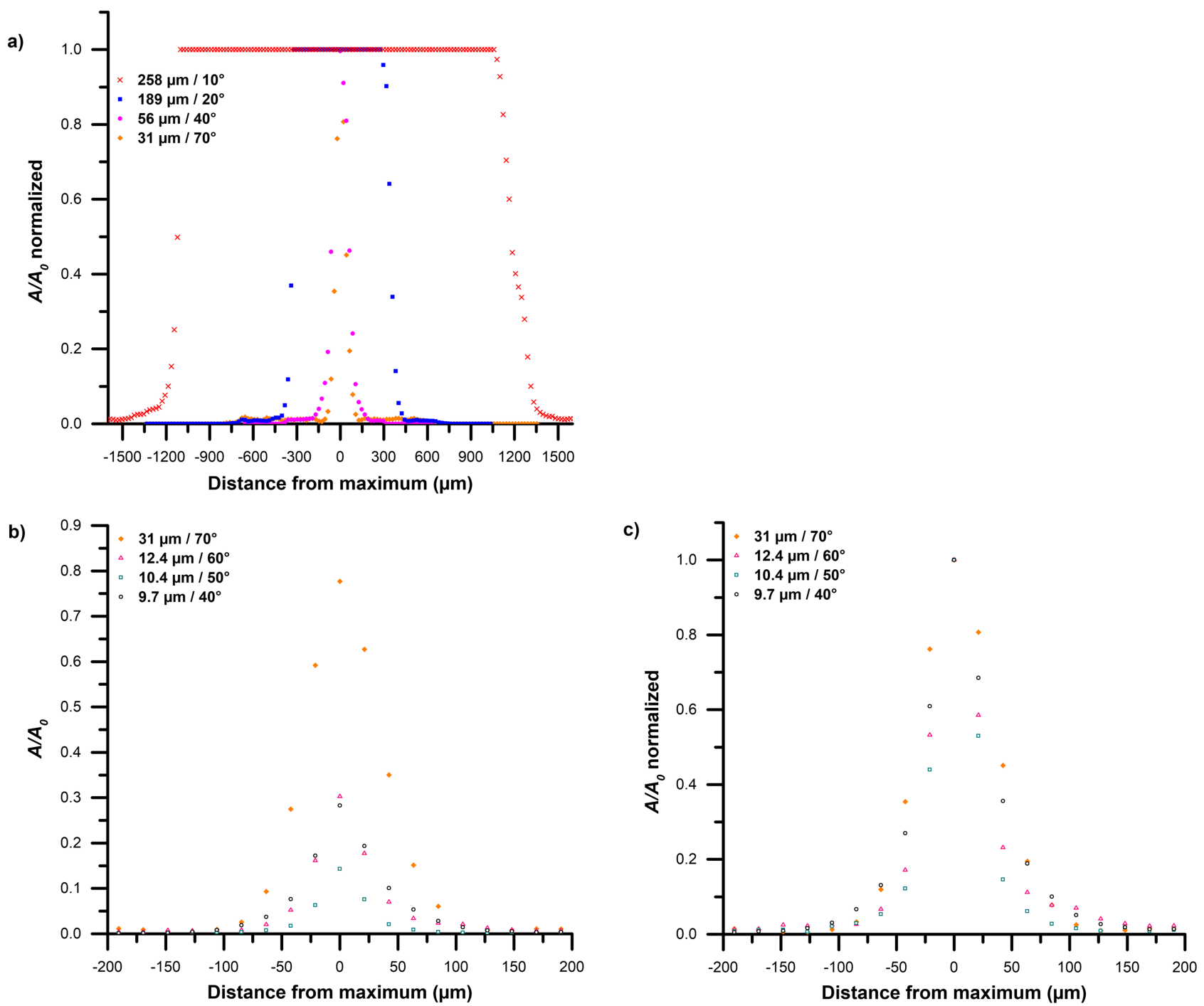

Figure 5. Macrocrack (a) and microcrack (b) activity profiles with different tilt angles (exposure time $=8 \mathrm{hr}$; pixel size $=21.17 \mu \mathrm{m}$ ). The macrocrack profiles were normalized to the maximum value as their maximum activity value was very close to 1 for any tilt angles. (c) Microcrack profiles normalized to the maximum value.

for both the experiment and the simulation. Those observations are also applicable with any tilt angle used (Figure 7b).

The experimental and simulated $i$ values obtained from the linear relation between the maximum activity value and the aperture of the microcracks are presented in Figure 7c. For $\sigma=90^{\circ}$, the experimental $i_{R}$ value is lower than that obtained from the simulations (about 55 against $100 \mu \mathrm{m}$ at low pixel sizes). A similar trend is observed for tilt angles $\sigma<90^{\circ}$. The experimental $i_{A}$ are roughly the same with any tilt angle (about $70 \mu \mathrm{m}$ ), while the simulated $i_{A}$ varies from 125 to $100 \mu \mathrm{m}$ (for a tilt angle of $30^{\circ}$ to $90^{\circ}$ ). Even if it seems that the fit is still decreasing at very low pixel sizes (under $20 \mu \mathrm{m}$ ), the pixel sizes which are the most used for scanning an autoradiograph and which correspond to the film resolution for ${ }^{14} \mathrm{C}$ are in the stabilized zone of $i_{R}$ or $i_{A}$ mentioned above. It is suggested to use the experimental mean value $i$ that most reliably approximates a realistic case, which is $70 \mu \mathrm{m}$. This mean value provides an uncertainty of $\pm 50 \%$ on the apparent aperture value, because $i$ (experimental and simulation) can vary between 50 and $120 \mu \mathrm{m}$ depending on the tilt.

\subsection{Application on a Real Sample: Grimsel Granodiorite}

A first example of application is shown in Figure S7. It corresponds to an autoradiograph of a weakly altered granodiorite sample from the Grimsel Test Site in Switzerland (Bradbury, 1989), containing only 

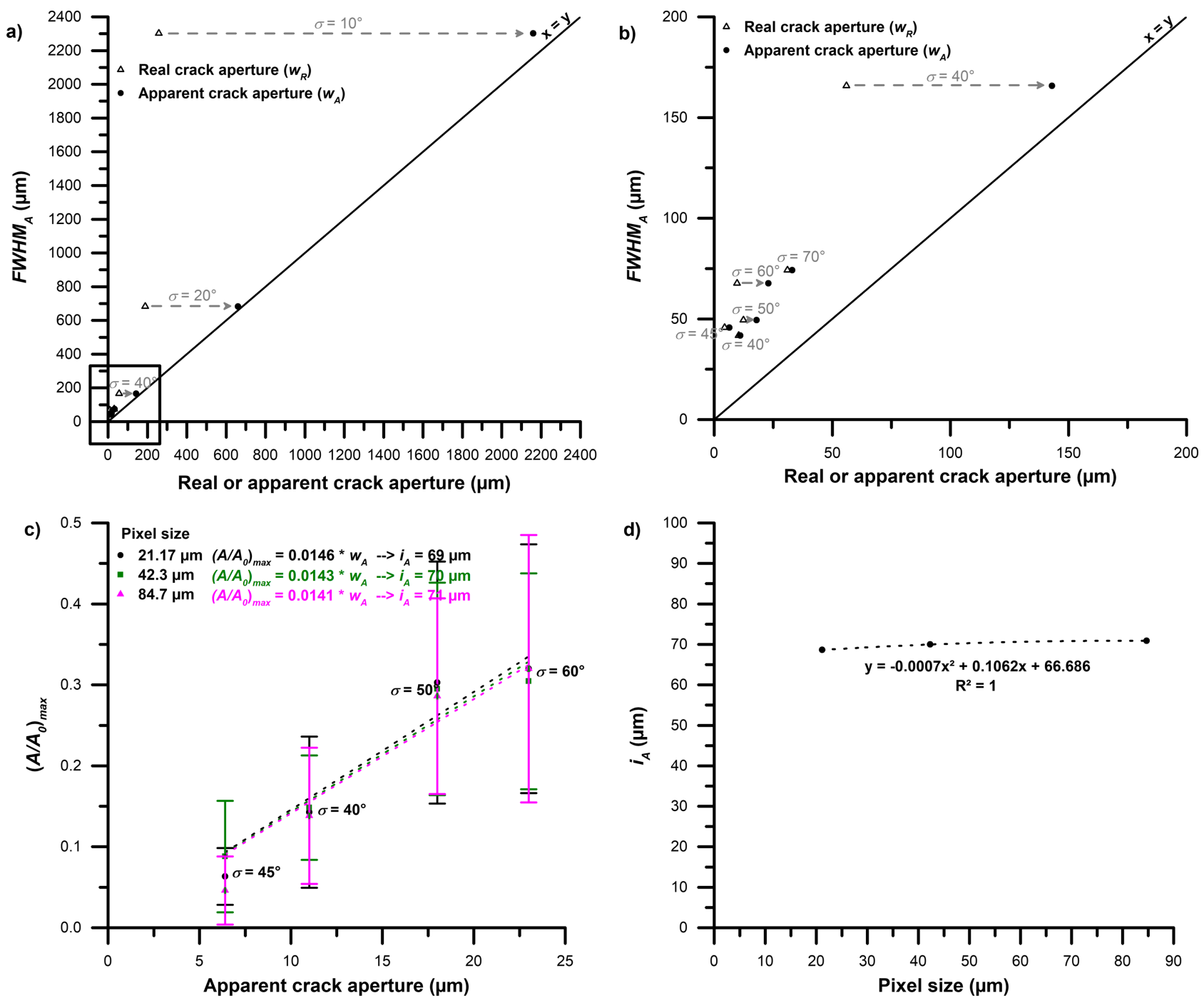

Figure 6. (a) $F W H M_{A}$ of cracks with different tilt angles (exposure time $=8 \mathrm{hr}$; pixel size $=21.17 \mu \mathrm{m}$ ) as a function of the real or apparent crack aperture, and (b) a magnification of the lower values (black box). The full line represents $F W H M$ equal to the measured apparent crack aperture. (c) Microcrack profile maximum activity values with different tilt angles (exposure time $=8 \mathrm{hr}$ ) as a function of the apparent crack aperture, for different pixel sizes. The dotted lines represent a linear fit of the data. (d) Apparent $i_{A}$ plotted as a function of pixel size. The dotted line represents a polynomial fit of the data, and its equation is shown.

microcracks. The microcracks were extracted using the Aphelion ${ }^{\circledR}$ software and the algorithm described in Mazurier et al. (2016). The gray levels of the skeletonized cracks were converted into apparent apertures using activities. Different $i$ were chosen for this conversion in order to compare them with the apparent microcrack apertures obtained using SEM. The SEM aperture statistics were obtained by scanning the thin sections with a set of parallel lines using the back scattered electrons (BSEi) mode (Cassiaux, 2004; Sardini et al., 1999). The comparison is shown in Figure 8a. Permeability $K$ of Grimsel granodiorite was also calculated, depending on the apparent aperture distributions obtained with $i$ (detailed calculations in Text S3; Figure 8b).

\subsubsection{Distribution of Apparent Microcrack Apertures}

First, using SEM or $i$ allows the detection and estimation of crack apertures smaller than $1 \mu \mathrm{m}$. Second, SEM detects a large amount of microcracks with an apparent aperture ranging from less than 0.1 to $1 \mu \mathrm{m}$, with a peak for microcrack apertures ranging from 0.1 to $0.5 \mu \mathrm{m}$, but it also detects microcrack apertures ranging from 1 to more than $2 \mu \mathrm{m}$ (Figure 8a). Different values for $i$ were chosen to estimate the microcrack apertures. The determination of $w_{A}$ using low values of $i$ (about 55 to $70 \mu \mathrm{m}$ ) is consistent with the aperture distribution obtained with SEM. Using higher values of $i$ overestimated the number of microcracks with $w_{A}$ 

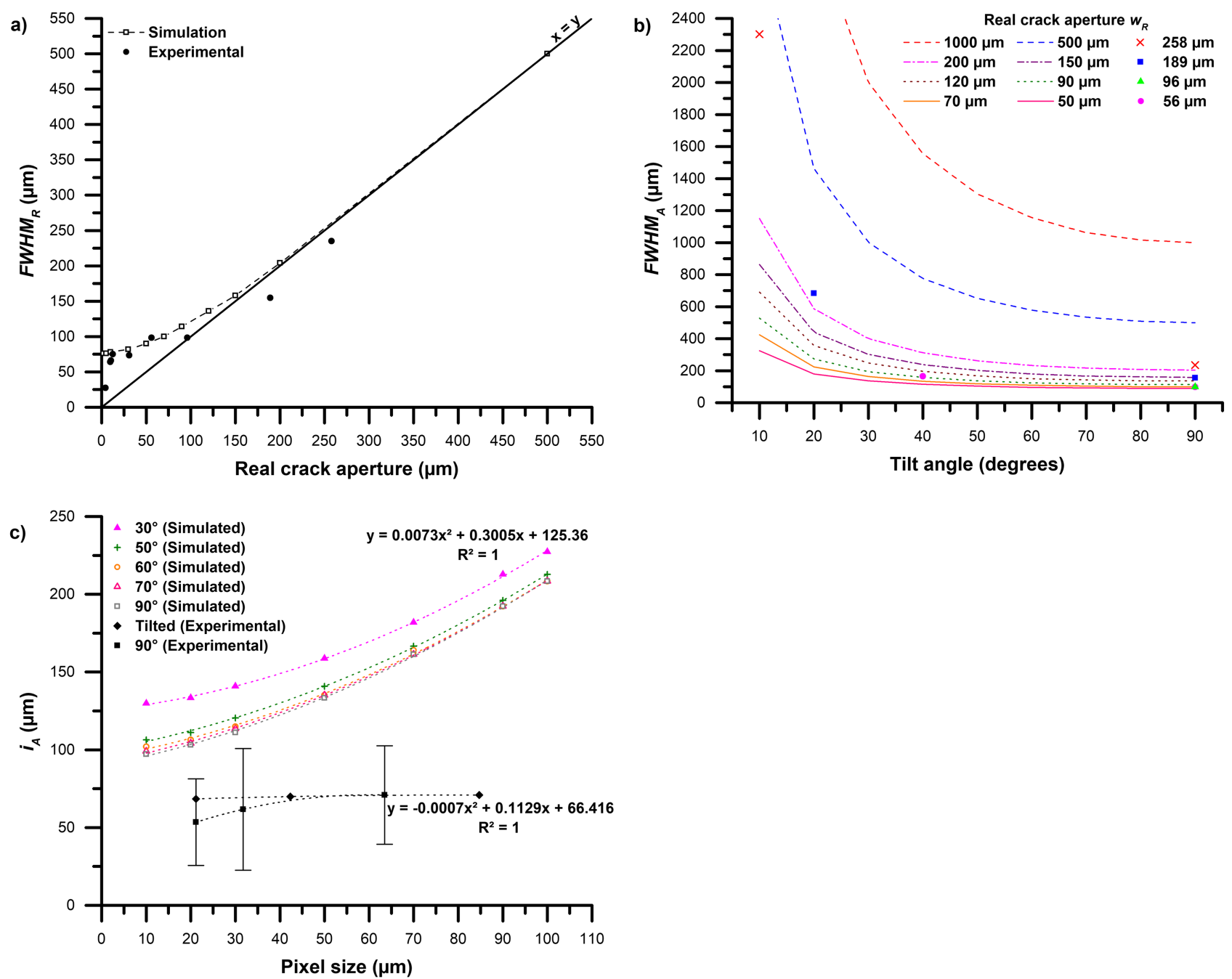

Figure 7. $F W H M_{R}$ (a) and $F W H M_{A}$ (b) of experimental and simulated perpendicular crack profiles, respectively, as a function of the real crack aperture and tilt angle (exposure time $=8 \mathrm{hr}$; pixel size $=21.17 \mu \mathrm{m} ; N_{T}=10^{7} ; b=2 \mu \mathrm{m}$ ). In (a) the full black line represents $F W H M$ equal to the real crack aperture.

(c) Values for apparent $i_{A}$ from experimental and simulated profiles plotted as a function of pixel size, for different tilt angles (exposure time $=8 \mathrm{hr} ; N_{T}=10^{7}$ ). The dotted lines represent a polynomial fit of the data.

ranging from 0.1 to $1.5 \mu \mathrm{m}$, also shifting the aperture distribution peak between 0.5 and $1 \mu \mathrm{m}$. This result confirms that using a value obtained from simulations for $i$ overestimates the smallest microcrack apertures. It seems thus more accurate to use a lower experimentally found value for $i$ to convert the activity profiles on the autoradiographic film into crack apertures.

\subsubsection{Permeability}

Permeability $\left(K, \mathrm{~m}^{2}\right)$ was calculated using the cubic law for a series of parallel cracks. The experimental probability density function of apparent aperture determined by autoradiography was used for the calculation. The fracture density employed for this calculation $\left(1.49 \mathrm{~mm} / \mathrm{mm}^{2}\right)$ was determined by image analysis of a section of the autoradiography. The resulting $K$ increased with the increase of $i$ values, varying between $3.01 \times 10^{-17}$ to $1.81 \times 10^{-16} \mathrm{~m}^{2}$ (for $i$ ranging from 55 to $100 \mu \mathrm{m}$; Figure $8 \mathrm{~b}$ ). This increase was expected as higher values of apparent microcrack apertures were obtained using higher values of $i$ (section 3.4.1), which indeed increases $K$. The values of $K$ calculated from the low values of $i$ are the values that most closely approximate the experimental He gas phase $K$ (between $10^{-18}$ and $10^{-17} \mathrm{~m}^{2}$ ) (Kelokaski et al., 2006) for the same granodiorite (Figure 8b). First, this confirms the accuracy of using low values of $i$ to determine crack aperture distributions. Second, the permeability determined experimentally is 1 order of magnitude lower than what was determined using autoradiographic analysis. This difference can be explained by the 
a)

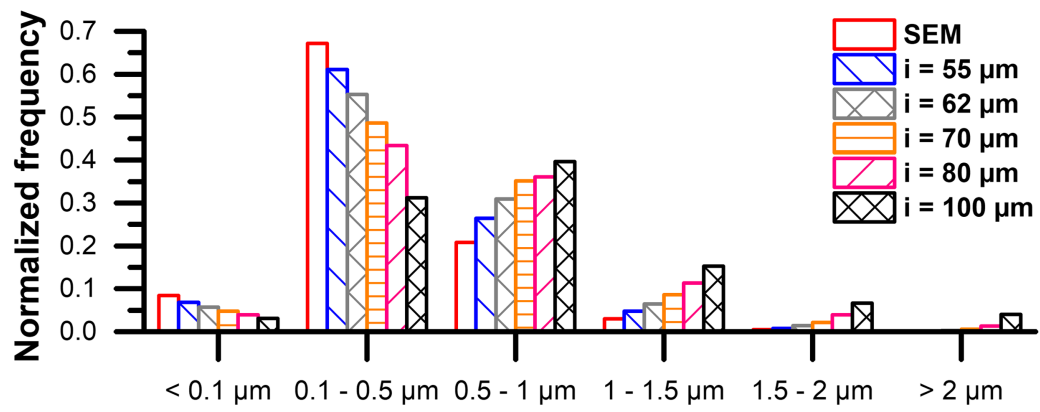

Apparent microcracks aperture $(\mu \mathrm{m})$

b)

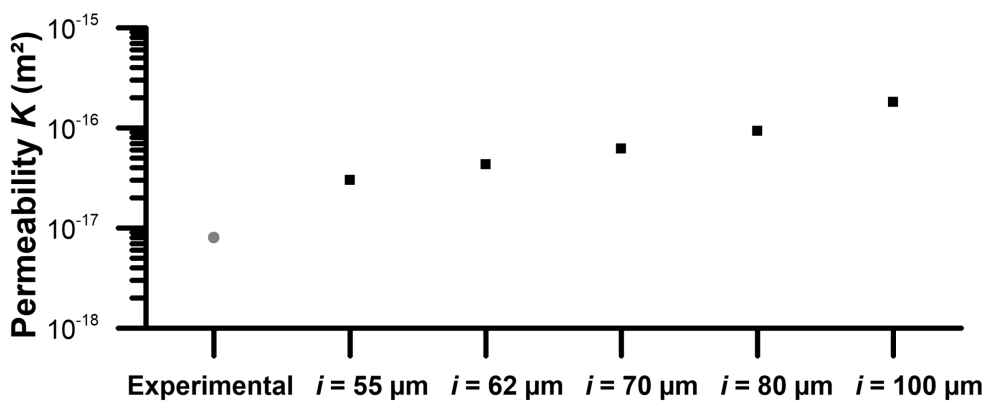

Figure 8. (a) Distribution of apparent microcrack apertures of Grimsel granodiorite obtained experimentally by SEM or using autoradiography with different $i$ values. (b) Permeability $K$ value of Grimsel granodiorite obtained using autoradiography with different $i$ values. The experimental He gas phase $K$ value from Kelokaski et al. (2006) is shown in gray (exposure time $=7$ days; pixel size $=21.17 \mu \mathrm{m}$ ).

3-D tortuosity of the crack network, and the fact that apparent apertures were used here to estimate $K$, and not real apertures.

\section{Discussion and Conclusions}

The experimental study of artificial cracks using the ${ }^{14} \mathrm{C}$-PMMA method provides an accurate determination of the apparent macrocrack or microcrack apertures. The results obtained by simulation on artificial cracks were similar to the experimental ones.

It was observed that it is difficult to obtain the desired aperture using Mylar or Al-foils as spacers for creation of artificial crack samples. Indeed, it is much more difficult to create an artificial crack with a small aperture because the relative uncertainty of the aperture increases as it moves toward the smaller apertures.

As in natural materials cracks exist in different inclinations, the artificial crack samples for this paper were cut using different tilt angles to study the impact of tilt angle on crack aperture estimation. The experimental and simulated results show an increase of the profile width of macrocracks at low tilt angles $\left(<50^{\circ}\right)$ leading to an overestimation of their aperture value. The maximum activity value of microcrack profiles increases when tilted, and thus the calculated $i$ value decreases, leading to an underestimation of their aperture. But this difference is not substantial when estimating the experimental microcrack apertures (normal $i_{R}=55 \mu \mathrm{m}$ and tilted $i_{A}=70 \mu \mathrm{m}$ ) as the microcracks present different tilt angles, which is more suitable to a natural case. The example application on Grimsel granodiorite confirmed this assumption.

Furthermore, the simulation illustrated that increase of the microcrack maximum activity is associated to the appearance of a profile asymmetry which is more pronounced for low tilt angles. The experimental profiles of microcracks did not, however, show any asymmetry. Thus, it seems unlikely that this method is able to measure the tilt angle of natural cracks and then the real crack aperture.

The major uncertainty of this advanced calibration method is related to $i$ factor for the estimation of microcrack apertures (see equation (2)). The use of the value $i=70 \mu \mathrm{m}$, knowing that $i$ can vary between 50 and $120 \mu \mathrm{m}$, depending on the tilt, gives an uncertainty of about $\pm 50 \%$ for the apparent aperture. 
To summarize, the experimental and simulated results show that the uncertainties on the crack aperture estimation are mainly related to the unknown tilt angle. However, apparent aperture represents a reliable indicator of real aperture distribution. For example, in the case of an isotropic rock, the tilt angle distribution is uniform, which means that one third of the cracks should have tilt angles ranging between $0^{\circ}$ and $30^{\circ}$, for which the apparent crack aperture estimation is biased. Thus, the section of the rock can be random to estimate the apparent or real aperture distribution. In the case of an anisotropic rock, the tilt angle distribution can be Gaussian, because cracks are expected to have a preferential orientation. It is then advised to use a rock section which is perpendicular to the anisotropy plane of the rock. Thus, the tilt angle will be close to $90^{\circ}$, meaning that the measured apparent crack apertures will be close to the corresponding real apertures.

This work was developed following the work of Mazurier et al. (2016) that have proposed that the main initiator of porosity development with weathering was the increase of the apertures of existing microcracks in the unweathered rock. It is therefore of a crucial importance to be able to accurately measure the apparent crack aperture distribution for evaluating physical parameters due to weathering.

Although the presented simulation approach allowed one to clarify the geometrical effects of a simple crack on its aperture estimation using the ${ }^{14} \mathrm{C}$-PMMA autoradiographic method, some additional investigations could be required.

$\bigcirc$ First, the crack apertures simulated in this paper were created as straight parallelepipedic volumes in order to use simple volumes in this first 3-D simulation approach. Indeed, at the scale of the analyzed pixel, many cracks can be considered as straight. However, it could be improved by taking into account the tortuosity of some cracks in natural materials, such as stylolite.

Second, the volume surrounding the crack was in this study always made of quartz. This means that the parameters used to determine $w_{A}$ consider that the rock is made only of quartz. However, the minerals forming the rock often have different properties in terms of their ability to be penetrated by electrons. For example, the $R_{m}$ of ${ }^{14} \mathrm{C} \beta^{-}$particles in quartz is $133 \mu \mathrm{m}$, while the $R_{m}$ is $99 \mu \mathrm{m}$ in biotite (Table S5). There is thus a need to simulate different media representing the minerals of the rock, in order to evaluate the sensitivity of the measured signal with mineral composition.

Third, another important point would be to consider crack volume which is partially filled with porous mineral aggregates. Such filled cracks are represented by various types of minerals, for example, clays, carbonates, or iron oxy-hydroxides, and are commonly observed in rocks (Rossi \& Graham, 2010). Even if it would be difficult to differentiate the filled crack to open ones on the autoradiographic film, the comparison between the apparent apertures of such filled cracks measured by SEM and the apparent apertures measured by ${ }^{14} \mathrm{C}$-PMMA autoradiographic method would help to quantify the porosity distribution of such fillings.

Finally, the effect of the roughness of sample surface which is controlled by the quality of the polishing can be verified. It has a direct impact on the gap separating the sample and the autoradiographic film. Different ranges of spacing can be simulated to study their effect on energy profiles. Preliminary results indicate that a spacing $<10 \mu \mathrm{m}$ does not significantly affect the estimation of the crack aperture.

As stated above, it seems unlikely to determine the tilt angle of natural cracks and then the real crack aperture by measuring the asymmetry coefficient. Another simple solution is then proposed here. It consists of (1) the realization of the autoradiograph of one polished sample section, (2) the repolishing of this same sample section to remove a controlled thickness of sample (e.g., $=t),(3)$ the realization of the second autoradiograph of this new polished sample section, and (4) the overlay of the two autoradiographs (using reference points). It will then allow one to measure the apparent displacement between the same cracks overlaid (e.g., $=d p$ ). This displacement is more important for lower tilt angles. Knowing the thickness removed and the displacement, it should be possible to determine the tilt angle $(\tan \sigma=t / d p)$, and then the real crack aperture.

The next step is to combine the results obtained with the ${ }^{14} \mathrm{C}$-PMMA method applied on natural rocks with those obtained by the Geant 4 simulations to draw a map of apertures of the connected crack network in the rock. The outcome of the application on Grimsel granodiorite was very encouraging. Applying this for each step of rock alteration (e.g., along a weathering profile) will allow one to follow the evolution of the porosity development (crack apertures) and thus to better understand the processes that lead to the changes in rock weathering and permeability. More generally, the knowledge of crack aperture distribution can be applied in another kind of model to better link pore microstructure to transport properties (Svensson et al., 2018; 
Trinchero et al., 2017). The possible errors on crack apertures are now more precisely known, enhancing the reliability of the method applied, thanks to the simulations. But it is also necessary to compare and combine this method with other methods, such as high-resolution SEM and XRCT. High-resolution SEM provides a submicron resolution of large images (centimeter areas) of thin sections allowing one to characterize a range of pore sizes from nanopores to macropores (Buckman et al., 2017). XRCT provides a 3-D observation of the nonconnected crack network. Furthermore, with XRCT providing a 3-D image of the rock sample, it is also possible to have information on the transport processes within the macrocrack networks of the rock, even if the resolution of this technique does not allow one to characterize the microcrack network (Johns et al., 1993; Ketcham \& Carlson, 2001; Mazurier et al., 2016).

The capability of superimposing the connected porosity with the mineralogy has already been demonstrated (Mazurier et al., 2016; Oila et al., 2005; Sardini et al., 2006), allowing one to observe the coevolution of the porosity (the amount of cracks and their apertures) with the mineralogy (chemistry and mineral specific porosity) during the weathering. A better characterization of this relation will allow a better understanding of the weathering processes. Indeed, the physical weathering impacts the rock and its minerals by breaking them, while the chemical weathering alters the primary minerals of the rock. Both induce important modifications to the rock (Taylor et al., 2001). Understanding these processes is primordial in being able to predict in long time scales the transformation of rocks or geomaterials and the rate of porosity formation. They allow on the one hand water flow or water holding capacity and on the other hand rock weathering, which are both key parameters of production or sustainability of soils and durability of materials.

\section{Acknowledgments}

The authors acknowledge financial support from the European Union (ERDF) and "Région Nouvelle Aquitaine." The authors gratefully appreciated the constructive and valuable comments from the Editor, Associate Editor, and anonymous reviewers to help improve this manuscript, as well as K.-H. Hellmuth for his thorough rereading of this article. M. Brouand, J.-C. Roussarie, and J.-M. Vergeau (Orano Bessines) are also thanked for their help on sample preparation. Data set and program codes presented as part of this study are available in the supporting information and from the GFZ Data Services repository at https://doi.org/10.5880/ fidgeo.2019.026 (for the data set) and at https://doi.org/10.5880/fidgeo.2019.027 (for the program codes). This product includes software developed by Members of the Geant4 Collaboration (http://cern.ch/geant4). Bonnet et al., 2019a, 2019b.

\section{References}

Agostinelli, S., Allison, J., Amako, K.A., Apostolakis, J., Araujo, H., Arce, P., et al. (2003). GEANT4-A simulation toolkit. Nuclear Instruments and Methods in Physics Research Section A: Accelerators, Spectrometers, Detectors and Associated Equipment, 506(3), 250-303. https://doi.org/10.1016/S0168-9002(03)01368-8

Bear, J., Tsang, C.-F., \& de Marsily, G. (1993). Flow and contaminant transport in fractured rocks. United States: Academic Press.

Bonnet, M., Sardini, P., Billon, S., Siitari-Kauppi, M., Kuva, J., Fonteneau, L., \& Caner, L. (2019a). Data set including raw data from the Geant 4 simulations (energy profiles), a file with the data from the energy profiles extracted with a code under Code::Blocks, 2 scans of autoradiographs (perpendicular and tilted cracks), and 1 image of two artificial crack samples. GFZ Data Services. http://doi.org/ 10.5880/fidgeo.2019.026

Bonnet, M., Sardini, P., Billon, S., Siitari-Kauppi, M., Kuva, J., Fonteneau, L., \& Caner, L. (2019b). Program codes used under Geant4 toolkit and IDE Code::Blocks to simulate the ${ }^{14} \mathrm{C}$-PMMA autoradiographic method and analyze the data, respectively, for better calibration of the determination of cracks aperture in rocks with this method. GFZ Data Services. http://doi.org/10.5880/ fidgeo.2019.027

Brace, W., \& Bombolakis, E. (1963). A note on brittle crack growth in compression. Journal of Geophysical Research, 68(12), 3709-3713. https://doi.org/10.1029/JZ068i012p03709

Bradbury, M. H. (1989). Laboratory investigations in support of the migration experiments at the Grimsel Test Site (No. 28) (p. 82). Würenlingen, Switzerland: Paul Scherrer Inst.(PSI).

Brown, S., Caprihan, A., \& Hardy, R. (1998). Experimental observation of fluid flow channels in a single fracture. Journal of Geophysical Research Solid Earth, 103(B3), 5125-5132. https://doi.org/10.1029/97JB03542

Brown, S. R. (1989). Transport of fluid and electric current through a single fracture. Journal of Geophysical Research Solid Earth, 94(B7), 9429-9438. https://doi.org/10.1029/JB094iB07p09429

Buckman, J., Bankole, S. A., Zihms, S., Lewis, H., Couples, G., \& Corbett, P. W. (2017). Quantifying porosity through automated image collection and batch image processing: Case study of three carbonates and an aragonite cemented sandstone. Geosciences, 7(3), 70. https://doi.org/10.3390/geosciences7030070

Cassiaux, M. (2004). Pétrographie et pétrophysique des matrices granitique: Relation entre porosité et propriétés de transport (Doctoral dissertation). Poitiers, France.

Cox, S., \& Scholz, C. (1988a). Rupture initiation in shear fracture of rocks An experimental study. Journal of Geophysical Research Solid Earth, 93(B4), 3307-3320. https://doi.org/10.1029/JB093iB04p03307

Cox, S., \& Scholz, C. (1988b). On the formation and growth of faults: An experimental study. Journal of Structural Geology, 10(4), 413-430. https://doi.org/10.1016/0191-8141(88)90019-3

Dagnelie, P. (1992). Statistique théorique et appliquée. Belgium: Les presses agronomiques de Gembloux Belgium.

Ghaffari, H., Sharifzadeh, M., \& Young, R. P. (2013). Complex aperture networks. Physica A: Statistical Mechanics and Its Applications, 392(4), 1028-1037. https://doi.org/10.1016/j.physa.2012.11.001

Ghaffari, H., \& Young, R. (2011). Topological complexity of frictional interfaces: Friction networks. ArXiv Preprint ArXiv, $1105,4265$. https://doi.org/10.5194/npg-19-215-2012

Grisak, G., \& Pickens, J. (1981). An analytical solution for solute transport through fractured media with matrix diffusion. Journal of Hydrology, 52(1-2), 47-57. https://doi.org/10.1016/0022-1694(81)90095-0

Grisak, G., \& Pickens, J.-F. (1980). Solute transport through fractured media: 1. The effect of matrix diffusion. Water Resources Research, 16(4), 719-730. https://doi.org/10.1029/WR016i004p00719

Hakami, E., \& Larsson, E. (1996). Aperture measurements and flow experiments on a single natural fracture (Vol. 33, pp. 395-404). Presented at the International Journal of Rock Mechanics and Mining Sciences \& Geomechanics Abstracts, Elsevier. https://doi.org/ 10.1016/0148-9062(95)00070-4 
Hellmuth, K.-H., Lukkarinen, S., \& Siitari-Kauppi, M. (1994). Rock matrix studies with carbon-14-polymethylmethacrylate (PMMA); method development and applications. Isotopenpraxis Isotopes in Environmental and Health Studies, 30(1), 47-60. https://doi.org/ $10.1080 / 00211919408046712$

Hellmuth, K.-H., \& Siitari-Kauppi, M. (1990). Investigation of the porosity of rocks. Impregnation with ${ }^{14}$ C-polymethylmethacrylate (PMMA), a new technique. (p. 67). Finland: Finnish Centre for Radiation and Nuclear Safety (STUK).

Hellmuth, K.-H., Siitari-Kauppi, M., \& Lindberg, A. (1991). Applications of the carbon-14-polymethylmethacrylate (PMMA) impregnation method in studies on porosity and matrix diffusion. MRS Online Proceedings Library Archive, 257, 649-656. https://doi.org/10.1557/ PROC-257-649

Hellmuth, K.-H., Siitari-Kauppi, M., \& Lindberg, A. (1993). Study of porosity and migration pathways in crystalline rock by impregnation with ${ }^{14}$ C-polymethylmethacrylate. Journal of Contaminant Hydrology, 13(1-4), 403-418. https://doi.org/10.1016/0169-7722(93)90073-2

Jamtveit, B., Kobchenko, M., Austrheim, H., Malthe-Sørenssen, A., Røyne, A., \& Svensen, H. (2011). Porosity evolution and crystallizationdriven fragmentation during weathering of andesite. Journal of Geophysical Research Solid Earth, 116(B12), 12. https://doi.org/10.1029/ 2011JB008649

Jamtveit, B., Putnis, C. V., \& Malthe-Sørenssen, A. (2009). Reaction induced fracturing during replacement processes. Contributions to Mineralogy and Petrology, 157(1), 127-133. https://doi.org/10.1007/s00410-008-0324-y

Johns, R. A., Steude, J. S., Castanier, L. M., \& Roberts, P. V. (1993). Nondestructive measurements of fracture aperture in crystalline rock cores using X ray computed tomography. Journal of Geophysical Research Solid Earth, 98(B2), 1889-1900. https://doi.org/10.1029/ 92JB02298

Keller, F., \& Waser, P. G. (1982). Quantification in macroscopic autoradiography with carbon-14-An evaluation of the method. The International Journal of Applied Radiation and Isotopes, 33(12), 1427-1432. https://doi.org/10.1016/0020-708X(82)90181-8

Kelokaski, M., Siitari-Kauppi, M., Sardini, P., Möri, A., \& Hellmuth, K.-H. (2006). Characterisation of pore space geometry by ${ }^{14}$ C-PMMA impregnation-Development work for in situ studies. Journal of Geochemical Exploration, 90(1-2), 45-52. https://doi.org/10.1016/j. gexplo.2005.09.005

Ketcham, R. A., \& Carlson, W. D. (2001). Acquisition, optimization and interpretation of X-ray computed tomographic imagery: Applications to the geosciences. Computers \& Geosciences, 27(4), 381-400. https://doi.org/10.1016/S0098-3004(00)00116-3

Kranz, R. L. (1983). Microcracks in rocks: A review. Tectonophysics, 100(1-3), 449-480. https://doi.org/10.1016/0040-1951(83)90198-1

Kuva, J., Hellmuth, K.-H., Sardini, P., \& Siitari-Kauppi, M. (2015). Verification of a simulation approach for estimating crack aperture using ${ }^{14}$ C-PMMA method. Journal of Coupled Systems and Multiscale Dynamics, 3(4), 333-340. https://doi.org/10.1166/ jcsmd.2015.1087

Leskinen, A., Penttinen, L., Siitari-Kauppi, M., Alanso, U., Garcia-Gutierrez, M., Missana, T., \& Patelli, A. (2007). Determination of granites' mineral specific porosities by PMMA method and FESEM/EDAX. Scientific Basis for Nuclear Waste Management XXX, 985, 599-604. https://doi.org/10.1557/PROC-985-0985-NN11-20

Mazurier, A., Sardini, P., Rossi, A. M., Graham, R. C., Hellmuth, K. H., Parneix, J. C., et al. (2016). Development of a fracture network in crystalline rocks during weathering: Study of Bishop Creek chronosequence using X-ray computed tomography and ${ }^{14} \mathrm{C}$-PMMA impregnation method. Bulletin, 128(9-10), 1423-1438. https://doi.org/10.1130/B31336.1

Oila, E., Sardini, P., Siitari-Kauppi, M., \& Hellmuth, K.-H. (2005). The ${ }^{14}$ C-polymethylmethacrylate (PMMA) impregnation method and image analysis as a tool for porosity characterization of rock-forming minerals. Geological Society, London, Special Publications, 240(1), 335-342. https://doi.org/10.1144/GSL.SP.2005.240.01.24

Putnis, A. (2002). Mineral replacement reactions: From macroscopic observations to microscopic mechanisms. Mineralogical Magazine, 66(5), 689-708. https://doi.org/10.1180/0026461026650056

Putnis, A. (2009). Mineral replacement reactions. Reviews in Mineralogy and Geochemistry, 70(1), 87-124. https://doi.org/10.2138/ rmg.2009.70.3

Regenauer-Lieb, K., Veveakis, M., Poulet, T., Wellmann, F., Karrech, A., Liu, J., et al. (2013b). Multiscale coupling and multiphysics approaches in Earth sciences: Applications. Journal of Coupled Systems and Multiscale Dynamics, 1(3), 281-323. https://doi.org/10.1166/ jcsmd.2013.1021

Regenauer-Lieb, K., Veveakis, M., Poulet, T., Wellmann, F., Karrech, A., Liu, J., et al. (2013a). Multiscale coupling and multiphysics approaches in Earth sciences: Theory. Journal of Coupled Systems and Multiscale Dynamics, 1(1), 49-73. https://doi.org/10.1166/ jcsmd.2013.1012

Rock, G. (2010). Rock to regolith conversion: Producing hospitable substrates for terrestrial ecosystems. GSA Today, 20(2), 5. https://doi. org/10.1130/GSAT57A.1

Rossi, A. M., \& Graham, R. C. (2010). Weathering and porosity formation in subsoil granitic clasts, Bishop Creek moraines, California. Soil Science Society of America Journal, 74(1), 172-185. https://doi.org/10.2136/sssaj2009.0146

Sammaljärvi, J. (2017). Structural characterisation via C-14-PMMA impregnation technique: Method and application development (Doctoral dissertation). Helsinki, Finland. Retrieved from http://hdl.handle.net/10138/228041

Sardini, P., Caner, L., Mossler, P., Mazurier, A., Hellmuth, K.-H., Graham, R. C., et al. (2015). Calibration of digital autoradiograph technique for quantifying rock porosity using ${ }^{14} \mathrm{C}$-PMMA method. Journal of Radioanalytical and Nuclear Chemistry, 303(1), 11-23. https:// doi.org/10.1007/s10967-014-3617-9

Sardini, P., Kuva, J., Siitari-Kauppi, M., \& Hellmuth, K.-H. (2014). A simplified simulation approach for estimating crack aperture using ${ }^{14}$ C-PMMA method. Journal of Coupled Systems and Multiscale Dynamics, 2(4), 244-255. https://doi.org/10.1166/jcsmd.2014.1053

Sardini, P., Sammartino, S., Meunier, A., \& Tévissen, E. (1999). Evolution of fluid pathways of Charroux-Civray tonalite (part II): Numerical study of microcrack networks. Physics and Chemistry of the Earth, Part A: Solid Earth and Geodesy, 24(7), 621-625. https:// doi.org/10.1016/S1464-1895(99)00090-3

Sardini, P., Siitari-Kauppi, M., Beaufort, D., \& Hellmuth, K.-H. (2006). On the connected porosity of mineral aggregates in crystalline rocks. American Mineralogist, 91(7), 1069-1080. https://doi.org/10.2138/am.2006.1939

Sausse, J., Jacquot, E., Fritz, B., Leroy, J., \& Lespinasse, M. (2001). Evolution of crack permeability during fluid-rock interaction. Example of the Brezouard granite (Vosges, France). Tectonophysics, 336(1-4), 199-214. https://doi.org/10.1016/S0040-1951(01)00102-0

Siitari-Kauppi, M. (2002). Development of ${ }^{14} \mathrm{C}$-polymethylmethacrylate method for the characterisation of low porosity media: Application to rocks in geological barriers of nuclear waste storage (Doctoral dissertation). Helsinki, Finland. Retrieved from https://helda.helsinki. fi/bitstream/handle/10138/21122/developm.pdf?sequence $=1$

Stoll, M., Huber, F. M., Trumm, M., Enzmann, F., Meinel, D., Wenka, A., et al. (2018). Experimental and numerical investigations on the effect of fracture geometry and fracture aperture distribution on flow and solute transport in natural fractures. Journal of Contaminant Hydrology.. https://doi.org/10.1016/j.jconhyd.2018.11.008 
Svensson, U., Löfgren, M., Trinchero, P., \& Selroos, J.-O. (2018). Modelling the diffusion-available pore space of an unaltered granitic rock matrix using a micro-DFN approach. Journal of Hydrology, 559, 182-191. https://doi.org/10.1016/j.jhydrol.2018.02.041

Taylor, G., Eggleton, R. A., \& Eggleton, R. A. (2001). Regolith geology and geomorphology. England: John Wiley \& Sons.

Trinchero, P., Molinero, J., Deissmann, G., Svensson, U., Gylling, B., Ebrahimi, H., et al. (2017). Implications of grain-scale mineralogical heterogeneity for radionuclide transport in fractured media. Transport in Porous Media, 116(1), 73-90. https://doi.org/10.1007/s11242016-0765-0

Tsang, Y., \& Witherspoon, P. A. (1983). The dependence of fracture mechanical and fluid flow properties on fracture roughness and sample size. Journal of Geophysical Research Solid Earth, 88(B3), 2359-2366. https://doi.org/10.1029/JB088iB03p02359

Tsang, Y. W., \& Witherspoon, P. (1981). Hydromechanical behavior of a deformable rock fracture subject to normal stress. Journal of Geophysical Research Solid Earth, 86(B10), 9287-9298. https://doi.org/10.1029/JB086iB10p09287

Velde, B. B., \& Meunier, A. (2008). The origin of clay minerals in soils and weathered rocks. Heidelberg: Springer Science \& Business Media

Vermilye, J. M., \& Scholz, C. H. (1995). Relation between vein length and aperture. Journal of Structural Geology, 17(3), 423-434. https:// doi.org/10.1016/0191-8141(94)00058-8

Voutilainen, M., Siitari-Kauppi, M., Sardini, P., Lindberg, A., \& Timonen, J. (2012). Pore-space characterization of an altered tonalite by Xray computed microtomography and the ${ }^{14}$ C-labeled-polymethylmethacrylate method. Journal of Geophysical Research Solid Earth, 117(B1), 14. https://doi.org/10.1029/2011JB008622

White, A. F., Bullen, T. D., Schulz, M. S., Blum, A. E., Huntington, T. G., \& Peters, N. E. (2001). Differential rates of feldspar weathering in granitic regoliths. Geochimica et Cosmochimica Acta, 65(6), 847-869. https://doi.org/10.1016/S0016-7037(00)00577-9

White, J., \& White, S. (1983). Semi-brittle deformation within the Alpine fault zone, New Zealand. Journal of Structural Geology, 5(6), 579-589. https://doi.org/10.1016/0191-8141(83)90070-6

\section{References From the Supporting Information}

Darcy, H. P. G. (1856). Les Fontaines publiques de la ville de Dijon. Exposition et application des principes à suivre et des formules à employer dans les questions de distribution d'eau, etc. V. Dalamont.

Eckerman, K., \& Sjoreen, A. (2004). Radiological toolbox user's manual. Department of Energy: United States.

Huitt, J. L. (1956). Fluid flow in simulated fractures. AIChE Journal, 2(2), 259-264. https://doi.org/10.1002/aic.690020224

Knoll, G. F. (2010). Radiation detection and measurement. United States: John Wiley \& Sons.

National Research Council (1996). Rock fractures and fluid flow: Contemporary understanding and applications. Washington, DC: National Academies Press.

Sarkar, S., Toksoz, M. N., \& Burns, D. R. (2004). Fluid flow modeling in fractures (p. 41). Massachusetts Institute of Technology. Earth Resources Laboratory. 